IZA DP No. 6047

Labour Market Under-Utilisation of

Recent Higher Education Graduates:

New Australian Panel Evidence

David Carroll

Massimiliano Tani

October 2011 


\title{
Labour Market Under-Utilisation of Recent Higher Education Graduates: New Australian Panel Evidence
}

\author{
David Carroll \\ Macquarie University \\ Massimiliano Tani \\ Macquarie University \\ and IZA \\ Discussion Paper No. 6047 \\ October 2011 \\ IZA \\ P.O. Box 7240 \\ 53072 Bonn \\ Germany \\ Phone: +49-228-3894-0 \\ Fax: +49-228-3894-180 \\ E-mail: iza@iza.org
}

\begin{abstract}
Any opinions expressed here are those of the author(s) and not those of IZA. Research published in this series may include views on policy, but the institute itself takes no institutional policy positions.

The Institute for the Study of Labor (IZA) in Bonn is a local and virtual international research center and a place of communication between science, politics and business. IZA is an independent nonprofit organization supported by Deutsche Post Foundation. The center is associated with the University of Bonn and offers a stimulating research environment through its international network, workshops and conferences, data service, project support, research visits and doctoral program. IZA engages in (i) original and internationally competitive research in all fields of labor economics, (ii) development of policy concepts, and (iii) dissemination of research results and concepts to the interested public.
\end{abstract}

IZA Discussion Papers often represent preliminary work and are circulated to encourage discussion. Citation of such a paper should account for its provisional character. A revised version may be available directly from the author. 


\title{
ABSTRACT \\ Labour Market Under-Utilisation of Recent Higher Education Graduates: New Australian Panel Evidence
}

\begin{abstract}
Recent research into the Australian labour market has reported that a substantial proportion of the tertiary-educated labour force is under-utilised relative to their level of education, echoing findings from an expanding international literature. This paper uses recent panel data from the 2010 Beyond Graduation Survey to analyse the incidence of labour force under-utilisation amongst recent Australian graduates and its effect on their wages, with an under-utilised graduate defined as a one who is in a job for which a sub-degree qualification would suffice. We find that $26 \%$ of graduates were under-utilised immediately after course completion and $15 \%$ were under-utilised three years later, although this varied considerably between subgroups. Recent graduates were much more likely to remain under-utilised than become under-utilised later in their careers. Being under-utilised appears to affect the earnings of different graduate age groups in different ways. Controlling for unobserved heterogeneity, we find that younger graduates tend to earn the same mean wages regardless of whether or not they are under-utilised, while older under-utilised bachelor degree graduates are at a significant wage disadvantage relative to their peers. This is suggestive of a graduate skills surplus and, by extension, inefficient public and individual investment in human capital.
\end{abstract}

JEL Classification: $\quad$ I23, J24

Keywords: graduate labour market, human capital, panel data

Corresponding author:

Massimiliano Tani

Department of Economics

Macquarie University

NSW 2109

Australia

E-mail: max.tani@mq.edu.au 


\section{Introduction}

Recent research into the Australian labour market has shown that holding a university degree is far from a guarantee of employment in a job that actually requires a university education. Different authors utilising different measurement techniques have estimated that anywhere from $20 \%$ to $45 \%$ of male university graduates and $17 \%$ to $38 \%$ of female university graduates are under-utilised in the Australian labour market with regard to their level of education-specific human capital (e.g., Kler, 2005; Mavromaras, et al., 2010), insofar that their respective levels of education exceed the requisite levels needed to perform their jobs (Linsley, 2005). These studies, along with a body of similar research conducted overseas (e.g., Alba-Ramirez, 1993; Dolton and Vignoles, 2000; Duncan and Hoffman, 1981; Rumberger, 1987), have generally concluded that under-utilised individuals are typically at an earnings disadvantage relative to their peers in appropriate employment. This suggests that the Australian labour market is characterised by under-utilised workers holding university degrees; a concerning fact considering that the various levels of Australian government invested more than 18 billion dollars in tertiary education in the 2009-10 financial year (ABS, 2011).

This existing literature into the under-utilisation of tertiary-educated workers in the Australian labour market focuses on university graduates in the sense of degree holders rather than in the sense of recent course completers. This second group will be the focus of our study. We believe that this group of recent higher education graduates is deserving of specific attention because of its relative homogeneity compared with the tertiary-educated workforce as a whole, in that its members are typically rich in education-specific human capital but generally poor in occupation-specific human capital. Our chosen focus on recent graduates is further justified on the basis that other studies have 
found that under-utilised workers are typically 'skilled' workers who lack experience, and that these individuals tend to move into higher-level jobs as their stock of occupation-specific human capital increases (e.g., Alba-Ramirez, 1993; Dolton and Vignoles, 2000; Sicherman, 1991; Sloane, Battu and Seaman, 1999). Investigating this in this context of recent graduates will allow us to see whether under-utilisation is indeed more common immediately following course completion or if it is a persistent, long-term feature of the labour market (e.g., Thurow, 1975). Specifically, this paper adds to the existing literature by investigating the incidence of under-utilisation in the Australian graduate labour market and its effect on earnings, immediately following course completion and again three years later, to determine whether these effects vary as graduates accumulate additional human capital in the form of on-the-job experience. Moreover, because human capital theory proposes that individuals will be paid more on the basis of additional education and, by implication, different educational content (Becker, 1964), we investigate whether these effects vary based on major field of study undertaken and level of degree completed. For this analysis we split our sample into four subgroups based on gender and age in order to investigate whether the effect of under-utilisation differs between 'traditional' and 'non-traditional' graduates of both genders.

The findings of this study have important theoretical and practical implications. From a theoretical standpoint, this study provides additional insights into the factors influencing the labour market outcomes for recent graduates, with specific focus on the manner by which employers reward different levels of educational attainment. From a higher education policy standpoint, this study may also help to inform debate concerning the optimal level of investment in higher education relative to other forms of post-compulsory education, such as vocational education and training (VET). 
This study is made possible by the availability of a new panel data set concerning the work and study activities of recent Australian graduates, the Beyond Graduation Survey (BGS), which was conducted in 2010 by Graduate Careers Australia (GCA). As this survey did not ask graduates whether they believed that they were in appropriate employment for their level of education, we categorise graduates as being appropriately utilised or under-utilised based on occupational skill levels in the Australian and New Zealand Standard Classification of Occupations (ANZSCO).

Our results indicate that around a quarter of recent Australian graduates are under-utilised immediately following course completion (26\%). The incidence of under-utilisation declined to $15 \%$ of the sample within three years of course completion, although the majority of these under-utilised graduates were also under-utilised three years earlier. With regard to its effect on earnings, underutilised graduates tended to earn lower wages than their counterparts in appropriate employment, even after controlling for unobserved heterogeneity in our sample. This earnings penalty was, however, only significant for older bachelor degree graduates of both genders. Curiously, older female postgraduates tended to earn higher mean wages if they were employed in non-graduate jobs.

As a final point in this introduction, it is important to note that the majority of the existing research in this field refers to over-education, in that an individual may be over-educated relative to the requirements of his or her current job. In this paper, we adopt the view that a graduate in a nongraduate job is not over-educated, per se, but rather that their productive capacity as a highly-skilled worker is under-utilised. As such, we refer to under-utilisation in this context throughout this paper.

The rest of this paper is organised as follows. Section 2 presents a review of relevant literature and outlines our contribution. Section 3 provides a brief overview of the data and variables used in this study. Section 4 outlines our estimation methodology. Section 5 presents results on the incidence of 
under-utilisation in the Australian graduate labour market and its effect on wages. Conclusions and implications for theory and higher education practice are presented in Section 6. Detailed definitions of the variables used in this study are presented in Appendix A.

\section{Background}

The idea of under-utilisation of university graduates was first introduced by Freeman (1976), who argued that during the 1970s the supply of graduates exceeded the demand for university-educated workers, forcing many into traditionally non-graduate jobs at relatively lower pay. Since then, a broad international literature has emerged concerning labour market under-utilisation, which generally concludes that a substantial proportion of the labour force possesses more education than is required to perform their jobs, and that individuals who are under-utilised in their jobs typically earn lower wages, ceteris paribus, than their counterparts in more appropriate employment (e.g., Alba-Ramirez, 1993; Dolton and Vignoles, 2000; Duncan and Hoffman, 1981; Kler, 2005; Linsley, 2005; Mavromaras et al., 2010; Rumberger, 1987). As noted by Mavromaras et al. (2010), much of this literature on under-utilisation has, for good reason, focused on university graduates. Firstly, university graduates have been the fastest-growing education group in Western labour markets in recent years, with the Australian labour market no exception; the proportion of workers in the Australian labour market with a higher education qualification increased from $28 \%$ to $37 \%$ over the past decade (ABS, 2001; 2010). ${ }^{1}$ Secondly, the presence of under-utilised graduates in the labour market is puzzling, considering that rates of return to degrees have been stable or increasing. Finally, investment in

\footnotetext{
${ }^{1}$ This includes all individuals in the labour force with an advanced diploma/diploma or higher qualification.
} 
university education is typically the highest per capita amongst all education categories, with underutilisation representing a poor return on this investment for both the individual and the economy.

Much of the variation in the incidence and effects of graduate under-utilisation reported in the literature, even within similar labour markets, may be attributable to the different methods used to identify and measure labour market mismatch. Three approaches dominate the literature; the Worker Self-Assessment (WA) method, the Realised Matches (RM) method and the Job Analysis (JA) method (Halaby, 1994; Hartog, 2000; Kler, 2005). The WA method, possibly the most utilised of the three (e.g., Dolton and Vignoles, 2000; Duncan and Hoffman, 1981; Linsley, 2005; Sloane, Battu and Seaman, 1996; Sloane, Battu and Seaman, 1999), measures under-utilisation by comparing the minimum level of education workers believe they require to perform their job to their actual education level. This measure has the advantage of being up-to-date and specific to an individual's job (Linsley, 2005), but may be subject to bias because it relies on the objectivity of respondents. Individuals tend to overstate the educational requirements of their jobs (Hartog, 2000) and may rely on benchmark jobs to assess the educational requirements of their own job (Dolton and Vignoles, 2000). Moreover, individuals who are under-utilised, and perhaps more negative about their jobs, may be less likely to respond to a survey on their labour market activities (Dolton and Vignoles, 2000), potentially introducing systematic non-response bias into the data. The RM method (e.g., Mavromaras et al., 2010; Messinis and Olekalns, 2006) is based on the mean education level in a particular occupation, ${ }^{2}$ with an individual considered under-utilised if he or she is more than one standard deviation above this mean education level for that occupation (Verdugo and Verdugo, 1989). The key limitations of the RM method include the arbitrariness of using standard deviations as cut-off points and also the

\footnotetext{
${ }^{2}$ The mean was the measure of central tendency first used by Verdugo and Verdugo (1989), although the mode has become a more common measure because the mean (and median) are too dependent on the shape of the underlying education distribution (Mavromaras et al., 2010).
} 
fact that occupations with greater proportions of under-utilised workers produce downward-biased estimates due to the mean education level for that occupation being artificially high (Dolton and Vignoles, 2000). Finally, the JA method (e.g., Kler, 2005; Rumberger, 1987) has the advantage of objectivity, being based on clear definitions developed by professional job analysts (Kler, 2003), but suffers from the disadvantage that it is based on the assumption that workers with the same job title are doing work of equal difficulty (Dolton and Vignoles, 2000).

As noted previously, the existing Australian literature concerning graduate under-utilisation has focused exclusively on degree holders in the Australian labour market, rather than recent higher education graduates. This omission is likely due to a lack of suitable data concerning the outcomes and activities of recent graduates in the years immediately following course completion. Large-scale panel studies of recent higher education graduates are practically unheard of in Australia, with the first truly national study of this kind, the BGS, conducted as recently as 2010. Notwithstanding this lack of specific research into the under-utilisation of recent Australian graduates, Kler (2005) and Mavromaras et al. (2010) have investigated the under-utilisation of tertiary-educated workers in the Australian labour market using two different data sets. ${ }^{3}$ Kler (2005) analysed the incidence of underutilisation amongst Australian-born graduates aged 20-64 years using data from the 1996 Census of Population and Housing, while Mavromaras et al. (2010) used panel data from the Household Income and Labour Dynamics in Australia (HILDA) survey to analyse the relationship between occupational mismatch and earnings for Australian graduates of working age. These authors also utilised different approaches to measuring graduate under-utilisation, which, as noted earlier, is common in the literature. Using the JA method, Kler (2005) concluded that 21\% of graduates were under-utilised

\footnotetext{
${ }^{3}$ Other studies (e.g., Green, Kler \& Leeves, 2004; Kler, 2007; Messinis, 2008; Piracha, Tani \& Vadean, 2010) have considered the labour market under-utilisation of first and second generation immigrants to Australia.
} 
(with the same incidence observed for males and females), although the incidence of under-utilisation was as high as $46 \%$ for male graduates and $38 \%$ for female graduates when using the RM method.

Mavromaras et al. (2010), also using the JA method, concluded that $20 \%$ of male graduates and $17 \%$ of female graduates in their sample were under-utilised. With regard to the effect of over-education on earnings, Kler (2005) concluded that the returns to years of surplus education are typically lower than the returns to years of required education (although this wage penalty varied based on the specific under-utilisation measure employed), while Mavromaras et al. (2010) identified significant negative returns to over-education for female graduates but not male graduates after controlling for individual fixed effects. As studies of graduate under-utilisation, both of these studies have limitations that need to be addressed. While the study by Kler (2005) includes a rich set of education variables (e.g., degree level, major field of study), it is limited in that it does not decompose university graduates into recent and non-recent graduates, and is based only on a single cross-section of data from a time when only 16\% of the Australian labour force possessed a higher education qualification (ABS, 2006a). The study by Mavromaras et al. (2010), although based on relatively recent data (2001-07) and utilising a panel estimation method that allows for the control of unobserved heterogeneity in the sample, is similarly unable to focus on recent university graduates and omits many of the key education variables present in the study by Kler (2005).

The study which comes closest to our own in terms of scope and focus is that of Dolton and Vignoles (2000), conducted with recent graduates in the UK. They used a panel data set from the 1980 National Survey of Graduates and Diplomates (covering the period 1980-86) in order to examine the incidence of under-utilisation and its effect on earnings for a cohort of UK graduates immediately after graduation and six years later, although, curiously, they did not use panel estimation 
methods to control for individual fixed effects. ${ }^{4}$ Using the WA method, they concluded that $38 \%$

percent of graduates were under-utilised in their first job after graduation and 30\% were under-utilised

six years later, and that under-utilised graduates earned lower wages than their counterparts in

appropriate employment. In addition to using more recent data collected in the under-researched

context of the Australian graduate labour market, we have adopted a panel estimation method that

allows for the control of unobserved heterogeneity in the sample and hence produce more robust

estimates than is possible with OLS. We have also extended the scope of the analysis conducted by

Dolton and Vignoles (2000) to investigate the effect of under-utilisation on the wages of graduates

from different major fields of study and different degree levels. Moreover, we split our sample into

four gender-age cohorts, with two representing the 'traditional' school-leaver cohort (i.e., those aged

25 and under at the time of graduation) and the other two representing the 'non-traditional' mature-

age cohort, in order to investigate whether under-utilisation affects each cohort differently. ${ }^{5}$ We

believe this focus on different graduate cohorts to be a major contribution of our paper.

\section{Data}

This study is based on data drawn from the 2010 BGS. Since 1972, graduates from Australian

higher education institutions have participated in a national census-style survey of their outcomes and activities approximately four months after course completion. ${ }^{6}$ The current incarnation of this national

\footnotetext{
${ }^{4}$ The reason for this is unclear from their paper. Dolton and Vignoles (2000) were able to control for a wide range of individual factors, such as degree class, total work experience, number of training days undertaken and so on, which may have minimised the impact of individual heterogeneity on their wage estimates.

${ }^{5}$ So-called 'Non-traditional students now comprise more than a third of enrolments in Australian higher education (Department of Education, Employment and Workplace Relations, 2010)

${ }^{6}$ Although the AGS is administered as a national census, the extent of non-response to the survey is typically around $40 \%$ for Australian domestic graduates (Graduate Careers Australia, 2010).
} 
graduate survey is known as the Australian Graduate Survey (AGS), conducted by GCA on a semiannual basis. ${ }^{7}$ The BGS was developed as a cohort-style follow-up to the 2007 AGS, whereby graduates who completed the AGS were invited to complete a survey concerning their work and study activities in the three years following course completion. ${ }^{8}$ Surveyed graduates were asked a range of questions concerning their activities on April 30 in 2008, 2009 and 2010, which were subsequently merged with data on their activities in 2007 based on a unique identifier assigned to each graduate. In all, more than $70 \%$ of the institutions who participated in the 2007 AGS also participated in the 2010 BGS, thus ensuring a nationally-representative sample of graduates from a diverse range of institutions. Graduates were invited to complete the survey by email. Graduates who completed the 2007 AGS were asked at the time to supply a long-term email address as a means of facilitating follow-up research, which was used by GCA as the primary means of inviting graduates to participate in the 2010 BGS. The survey response rate was approximately $15 \% .{ }^{9}$ An examination of the sample characteristics for the Australian domestic graduates who completed the 2007 AGS and the 2010 BGS indicated that the latter was broadly representative of the former. ${ }^{10}$ Due to the under-representation of overseas graduates in the sample, as well as the increased potential for sampling bias resulting from the difficulty in contacting overseas graduates following their repatriation, all overseas graduates were excluded from the analysable sample. Although the long-term email approach utilised by the survey administrators likely reduced the potential for bias stemming from graduate mobility (i.e., moving house after graduation and failing to leave a forwarding address), it should be noted that graduates

\footnotetext{
${ }^{7}$ The AGS is administered semiannually because most Australian higher education institutions have two major graduation rounds in a given year.

${ }^{8}$ A large-scale pilot of the BGS was undertaken in 2009. This study is based on data from the 2010 BGS, which was the first year of the survey proper.

${ }^{9}$ Due to some of the data collection fieldwork being carried out by participating higher education institutions, the precise number of graduates who were sent but did not receive an invitation to participate in the survey is not known. As a result, the actual survey response rate may be higher than the figure given.

${ }^{10}$ Guthrie and Johnson (1997) established that the AGS is not subject to serious non-response bias.
} 
who had achieved labour market success may have been more likely to respond to this follow-up survey (Dolton and Vignoles, 2000), which would impact the generalisability of the results presented herewith. Wage estimates have been presented along with their standard errors throughout this paper so that readers may draw their own conclusions concerning the robustness of our results.

Because this study focuses on the Australian graduate labour market, graduates who were not in paid employment in 2007 were removed from the sample, as were graduates who were employed overseas at any time during the three-year period under examination. Wages above the 99th percentile were removed, as were those below the Australian minimum hourly wage in 2007 and $2010 .{ }^{11}$ This resulted in an analysable sample of 3,586 graduates, including 267 graduates who were in paid employment in 2007 but not in 2010. One limitation of the BGS and its progenitor, the AGS, is that neither survey captures the sum total of an individual's labour market experience. To address this, age was used as a proxy for experience. This limitation aside, the BGS provides rich data for other key human capital variables, including field of study and degree level. The variables used in this paper are defined in Appendix A, with descriptives for the 2007 and 2010 subsamples presented in Table 1.

[Table 1 here]

We utilised the JA method to construct the under-utilisation variables of interest in this paper, with occupational skill levels drawn from ANZSCO serving as a basis. ${ }^{12}$ The five ANZSCO skill levels

\footnotetext{
${ }^{11}$ This involved the removal of cases with an hourly wage below $\$ 13.46$ or above $\$ 96.54$ in 2007, and below $\$ 14.30$ or above $\$ 117.92$ in 2010 .

${ }^{12}$ In the context of ANZSCO, a 'skill level' is a function of both the range and complexity of tasks performed in a particular occupation, with a greater range and complexity of tasks according with a higher occupational skill level (Australian Bureau of Statistics, 2006b).
} 
were condensed into a binary dummy variable for this study, ${ }^{13}$ with graduates in occupations

classified as Skill Level 1, commensurate with a bachelor degree or higher qualification, considered appropriately utilised with regard to their level of education, while graduates in occupations classified within the four lower skill levels were considered under-utilised. Based on our chosen definition, 923 graduates in our sample were under-utilised in 2007 and 497 were under-utilised in 2010.

Graduates’ specific occupations in 2007 and 2010 were coded manually on the basis of two openresponse items: what was the full title of your occupation and what were the main tasks or duties in your job. Graduates were instructed to describe their tasks and duties as fully as possible so as to facilitate accurate occupational coding. ${ }^{14}$ By coding graduates into occupational categories (and, by extension, different skill levels) on the basis of their self-described tasks or duties in addition to the title of their occupation, we believe that we are addressing the main criticism associated with the use of the JA method - that it is based on the assumption that workers with the same occupation title are doing work of equal difficulty—and propose that our approach represents a middle ground between the JA and WA methods. We concede that this approach is still sensitive to the creativity with which graduates describe their tasks or duties and, therefore, is still subject to bias; however, this is addressed in our analysis by the inclusion of error terms in the earnings functions.

\section{Estimation methodology}

\footnotetext{
${ }^{13}$ Skill Level 1 is commensurate with a bachelor degree or higher qualification; Skill Level 2 with an Associate Degree, Advanced Diploma or Diploma; Skill Level 3 with an Australian Qualifications Framework (AQF) Certificate IV; Skill Level 4 with an AQF Certificate III or II; Skill Level 5 with an AQF Certificate I or compulsory secondary education (Australian Bureau of Statistics, 2006b).

${ }^{14}$ A graduate with the occupation title 'Manager' with the duties of a finance manager will, for example, be assigned a higher skill level than a similarly titled graduate with the duties of a restaurant manager.
} 
Following the econometric approach employed by Dolton and Vignoles (2000), ${ }^{15}$ we begin our investigation into the wage effects of under-utilisation by estimating the following earnings function for recent graduates separately for their 2007 and 2010 jobs using OLS:

$$
\ln Y_{i}=\alpha_{0}+\alpha U_{i}+\beta X_{i}+\varepsilon_{i}
$$

where $\ln Y_{i}$ is the $\log$ of hourly earnings and $U_{i}$ is the under-utilisation dummy variable described in the previous section. $X_{i}$ is a vector of personal, educational and occupational characteristics for graduate $i$ that are used as control variables, including age, sex, major field of study, degree level, employment status during final year of study, job tenure, self-employment, working on a part-time or casual basis, location of employment and employment sector. $\varepsilon_{i}$ is a conventional error term. Because 267 graduates in the initial sample were no longer working in 2010, it is possible that OLS estimation will yield biased and inconsistent results because graduates who were still working in 2010 may represent a non-random subsample of the complete sample. To address this, we use the Heckman (1979) two-stage correction technique to control for selection bias in our 2010 subsample. It is well established that this technique yields consistent estimates. ${ }^{16}$

Because OLS estimation of panel data typically yields biased estimates due to the presence of unobserved time-invariant heterogeneity, we also employ fixed-effects panel estimation to produce more robust estimates. ${ }^{17}$ This takes the following form:

$$
\ln Y_{i t}=\alpha_{0}+\alpha U_{i t}+\beta X_{i t}+\delta_{t}+c_{i}+u_{i t}
$$

\footnotetext{
${ }^{15}$ Eqn. (1) is the authors' formulation of the estimation approach described by Dolton and Vignoles (2000).

${ }^{16}$ The variable included in the selection equation but excluded from the wage equations was a dummy variable indicating whether a graduate was engaged in a non-employment activity at some point between the two survey periods. Our reasoning is that graduates who are so engaged would be less likely to be in employment in 2010 than graduates who remained in the workforce throughout.

${ }^{17}$ The appropriateness of using a fixed effects model over a random effects model in this case was established by performing a Hausman test on the estimates of both models (see Green, 2008). We also estimated a random effects model augmented with a Mundlak (1978) correction to control for the presence of unobserved timeinvariant heterogeneity but, as expected, this produced identical estimates to our fixed effects model.
} 
where $\delta_{t}$ is the time-specific effect, $c_{i}$ is the time-invariant individual fixed effect and $u_{i t}$ is an idiosyncratic error term. Other terms are as previously defined but with the subscript $t$ indicating survey year. We have modelled a time-specific effect in this earnings function because we suspect that there are time-specific factors that impact upon all individuals in our sample in the same way, such as the state of the labour market at the time of each survey period.

\section{Results}

\subsection{Incidence of graduate under-utilisation}

Consistent with the existing literature, we find that a substantial proportion of the graduates in our sample were under-utilised for their jobs, with around a quarter (26\%) in jobs that did not require a university education immediately following course completion (Table 2). Also in line with other studies, the incidence of under-utilisation declined in the years following course completion, with $15 \%$ of the graduates in our sample under-utilised in their 2010 jobs. This suggests that graduates are most likely to be under-utilised immediately following course completion when their stock of occupation-specific human capital and general labour market experience is at its lowest level.

Of more interest, however, is the extent to which the incidence of under-utilisation varies between different subgroups in our sample. Younger graduates of both genders were much more likely to be under-utilised than their older counterparts immediately following course completion, although the incidence of under-utilisation fell notably for young graduates within three years. Young males were less likely to be under-utilised than older males three years after course completion, while younger females remained more likely to be under-utilised than older females. Older graduates of both genders 
were equally likely to be under-utilised immediately following course completion, although older males were slightly more likely to be under-utilised than their female counterparts within three years.

Much variation was observed with regard to major field of study, with 34 percentage points separating the field of study with the lowest incidence of under-utilisation (education) and that with the highest (society and culture) immediately following course completion. Graduates from the fields of creative arts and sciences were also quite likely to be under-utilised in their jobs immediately following course completion, with graduates from the fields of health and engineering less likely. Less variation was observed between fields three years after course completion, with 15 percentage points separating the fields with the highest incidence of under-utilisation (society and culture; creative arts) and the lowest (education). Under-utilisation was also observed to decrease inversely with degree level, with graduates possessing higher qualifications increasingly less likely to be underutilised in their jobs. This was observed both immediately after course completion and again three years later, although, as with major field of study, the variation between degree levels was reduced three years later. Surprisingly, graduates who were in paid work during their final year of study were consistently more likely to be under-utilised than those who were not, in spite of the former cohort presumably having more general labour market experience.

When examined based on occupational characteristics, we see that self-employed graduates were less likely to be under-utilised than graduates employed by firms, while graduates employed on a parttime or casual basis were more likely to be under-utilised than their full-time employed counterparts. Employment sector saw the greatest variation in the incidence of under-utilisation, with 67 percentage points separating the sector with the highest under-utilisation (accommodation and food services) and that with the lowest (mining) immediately following course completion. Even three years later, 41 
percentage points separated the extremes of the accommodation and food services and professional services sectors, which recorded the highest and lowest incidences of under-utilisation respectively.

[Table 2 here]

Table 3 details graduates’ transitions to and from under-utilisation in 2007 and 2010. Perhaps not surprisingly, the vast majority of graduates who were in appropriate employment immediately following course completion were still in appropriate employment three years later, with only $8 \%$ of these graduates indicating that they were in a lower-skilled job three years later. Of those graduates who were under-utilised in their jobs immediately following course completion, $65 \%$ had managed to secure more appropriate employment within three years, although the converse to this is that around a third (35\%) of graduates who were under-utilised immediately after course completion were still under-utilised three years later.

[Table 3 here]

\subsection{Effect of under-utilisation on wages}

Much of the existing literature has concluded, as noted earlier, that under-utilised individuals typically earn lower wages, ceteris paribus, than individuals in more appropriate employment for their level of education. As shown in the '2007' OLS estimates column of Table 4, under-utilised graduates in all but one of the gender-age subgroups earned lower wages than their better-utilised counterparts 
immediately following course completion, even after controlling for an extensive range of personal, education and employment characteristics. ${ }^{18}$ Only younger male graduates were, on average, not penalised for being under-utilised relative to their level of formal education. The relative hourly wage penalty for being under-utilised appeared broadly consistent for female graduates regardless of their age group, with the strongest wage penalty observed for under-utilised male graduates aged over 25 years. As shown in the '2010' OLS estimates column of Table 4, under-utilised graduates in all of the gender-age subgroups under examination earned lower wages than their counterparts in more appropriate employment three years after course completion. As discussed earlier, we employ panel estimation to control for unobserved time-invariant heterogeneity in the sample. From Table 4, it can be seen that fixed-effects estimation of Eqn. (2) produces weaker estimates than the corresponding OLS models, which suggests that controlling for unobserved heterogeneity in the sample removes at least some of the wage effect of under-utilisation observed previously. ${ }^{19}$ It is noteworthy that, even after controlling for unobserved systematic differences, older under-utilised graduates of both genders remained at a significant wage disadvantage relative to those in more appropriate employment.

[Table 4 here]

We next investigate the impact of field of study on the wage effects of under-utilisation by incorporating four under-utilisation*field of study interaction terms into our earnings functions. In deference to sample size considerations, we combined the seven major fields of study included as control variables in our initial wage equations into three dummy variables: technical majors, which

\footnotetext{
${ }^{18}$ These variables are defined in Appendix A.

${ }^{19}$ Mavromaras et al. (2010) made similar observations about Australian graduates.
} 
includes sciences, information technology and engineering fields, and health/education and society and culture/arts, both of which are self explanatory. The field of management and commerce was the omitted base case. As shown in Table 5, under-utilised management and commerce graduates earned less than their counterparts in appropriate employment immediately after course completion, implied by the negative coefficient on the under-utilised dummy variable. Only younger male graduates were not so penalised. Conversely, younger female society and culture/arts graduates who were underutilised actually earned higher mean wages than their better-utilised counterparts, as did older male health/education graduates. Three years after course completion, younger female and older male management and commerce graduates of both genders remained at a wage disadvantage as a result of being under-utilised relative to their education level, while younger female society and culture/arts graduates who were under-utilised continued to earn higher mean wages than their better-utilised counterparts. After controlling for unobserved heterogeneity in the sample, none of these effects were statistically significant. This result may suggest that the wage penalty for under-utilisation is not concentrated among graduates from any particular field of study.

[Table 5 here]

We also investigate the impact of degree level on the wage effects of under-utilisation by incorporating under-utilisation*postbaccalaureate study interaction terms into our earnings functions. ${ }^{20}$ For the same reason as before, we combined the four degree levels from the earlier wage equations into a single dummy variable for postbaccalaureate degree, with pass bachelor degree

\footnotetext{
${ }^{20}$ In the context of this study, postbaccalaureate degrees are those beyond the completion of an ordinary or pass bachelor degree.
} 
remaining the omitted base case. As shown in Table 6, under-utilised younger female bachelor degree graduates were at an earnings disadvantage relative to their better-utilised peers immediately after course completion, as were older female postgraduates. Three years after course completion, underutilised bachelor degree graduates in all of the gender-age subgroups under examination earned lower wages than their counterparts in more appropriate employment. After controlling for unobserved heterogeneity in the sample, however, only the under-utilised bachelor degree graduates aged over 25 years remained at a significant earnings disadvantage. Curiously, older female postgraduates who were under-utilised relative to their level of formal education actually received significantly higher mean wages than their ostensibly better-utilised counterparts.

[Table 6 here]

\section{Conclusions and implications}

These results highlight several key features of under-utilisation in the Australian graduate labour market. First, around a quarter of the graduates in our national sample were under-utilised in their jobs immediately after graduation, with under-utilisation more common amongst younger graduates of both genders; graduates from the study fields of society and culture, creative arts and sciences; graduates employed on a part-time or casual basis and graduates employed in the accommodation and food services, wholesale and retail trade, art and recreation services, administration, and transport and warehousing sectors. Within three years of graduation, however, the incidence of under-utilisation declines to $15 \%$ of our sample, representing a decrease in the incidence of under-utilisation of more 
than $40 \%$ over this period. Second, the majority of graduates who were under-utilised three years after course completion were also under-utilised immediately following course completion, which suggests that recent graduates are much more likely to remain under-utilised than to become under-utilised later in their careers. Third, with regard to wage effects, under-utilised graduates appear to earn lower wages overall than their counterparts in appropriate employment, even after controlling for unobserved heterogeneity in our sample, although this average earnings penalty was only observed for older graduates who had completed bachelor degrees. Notably, older female postgraduates who were under-utilised earned higher mean wages than their counterparts in appropriate graduate employment, which paints a somewhat troubling picture regarding the career opportunities for this cohort.

From a theoretical perspective, these wage results may support a signalling interpretation of the role of education in wage determination, under which employers use educational attainment as an indicator of ability due to the difficulty in directly observing the latter (Spence, 1973). Because older graduates typically have a more extensive work history than younger graduates, employers have better information about their real productivity and need not rely heavily on educational attainment as a signal of ability. This could explain why younger graduates are equally remunerated, on average, while older under-utilised graduates are at an earnings disadvantage relative to their better-utilised peers. The declining incidence of under-utilisation in the years immediately following graduation is consistent with the prediction in human capital theory that under-utilisation decreases with job experience and that individuals may, at the start of their career, accept jobs below their education level with the intention of accumulating work experience and skills (Piracha, Tani and Vadean, 2010). From a higher education policy standpoint, these results may be cause for some concern. Because higher education qualifications are unlikely to confer a substantial productivity advantage if they are 
surplus to the skill requirements of a graduate's occupation, the extent of graduate under-utilisation observed in this study is suggestive of, on one hand, a skills surplus in the Australian graduate labour market and, on another, inefficient public and individual investment in human capital. With around a quarter of recent graduates finding themselves in employment for which a sub-degree qualification would suffice and much greater under-utilisation observed in certain fields of study, even several years after course completion, the Australian Government may be well advised to encourage greater participation in VET, while at the same time limiting the supply of graduates from study fields with a clear and persistent skills surplus through appropriate higher education funding mechanisms.

Finally, while this study has provided new insights regarding under-utilisation in the Australian graduate labour market, a three-years-out perspective may not be sufficient basis on which to draw conclusions on graduate under-utilisation in the longer term. It is expected that similar data drawn from a planned five-year follow-up study of Australian graduates ${ }^{21}$ will provide further evidence as to whether under-utilisation is a persistent feature of the graduate labour market, or is a temporary mismatch restricted mainly to recent course completers with limited post-study experience.

${ }^{21}$ The 2011 BGS is planned as a five-year follow-up to the 2006 AGS. 


\section{References}

Alba-Ramirez, A. (1993). “Mismatch in the Spanish labour market: Overeducation?”, The Journal of Human Resources, 27(2), 259-278.

Australian Bureau of Statistics (2001; 2006a; 2010). Education and Work, Australia (No. 6227.0).

Canberra: Australian Bureau of Statistics.

Australian Bureau of Statistics (2006b). Australian and New Zealand Standard Classification of

Occupations, First Edition (No. 1220.0). Canberra: Australian Bureau of Statistics.

Australian Bureau of Statistics (2011). Government Finance Statistics, Education, Australia, 2009-10

(No. 5518.0.55.001). Canberra: Australian Bureau of Statistics.

Becker, G.S. (1964). Human Capital: A Theoretical and Empirical Analysis with Special Reference to

Education. New York: National Bureau of Economic Research.

Department of Education, Employment and Workplace Relations (2010). Students: Selected Higher

Education Statistics. Canberra: Department of Education, Employment and Workplace Relations.

Dolton, P., and Vignoles, A. (2000). "The incidence and effects of overeducation in the U.K. graduate labour market”, Economics of Education Review, 19(2000), 179-198.

Duncan, G.J., and Hoffman, S.D. (1981). “The incidence and wage effects of overeducation”, Economics of Education Review, 1(1), 75-86.

Freeman, R.B. (1976). The Over-educated American. New York: Academic Press.

Graduate Careers Australia (2010). Graduate Destinations 2009. Melbourne: Graduate Careers Australia. 
Green, C., Kler, P., and Leeves, G. (2004). “Overeducation and the assimilation of recently arrived immigrants: Evidence from Australia”, Centre for Economic Policy Modelling, The University of Queensland, Working Paper No. 4.

Green, W.H. (2008). Econometric Analysis (6th ed). Upper Saddle River: Prentice Hall.

Guthrie, B., and Johnson, T.J. (1997). Study of Non-Response to the 1996 Graduate Destination Survey. Canberra: Department of Employment, Education, Training and Youth Affairs.

Halaby, C.N. (1994). “Overeducation and skill mismatch”, Sociology of Education, 67, 47-59.

Hartog, J. (2000). “Overeducation and earnings: Where are we, where should we go”, Economics of Education Review, 19(2), 131-147.

Heckman, J.J. (1979). “Sample selection bias as a specification error”, Econometrica, 47(1), 153-161.

Kler, P. (2003). “Is there a 'rising tide’ of graduate overeducation in Australia”, Centre for Economic Policy Modelling, The University of Queensland, Working Paper No. 2.

Kler, P. (2005). “Graduate overeducation in Australia: A comparison of the mean and objective methods”, Education Economics, 13(1), 47-72.

Kler, P. (2007). “A panel data investigation into overeducation among tertiary educated Australian immigrants”, Journal of Economic Studies, 34(3), 179-193.

Linsley, I. (2005). “Causes of overeducation in the Australian labour market”, Australian Journal of Labour Economics, 8(2), 121-143.

Mavromaras, K., McGuinness, S., O’Leary, N., Sloane, P., and Wei, Z. (2010). “Job mismatches and labour market outcomes: Panel evidence on Australian university graduates”, National Institute of Labour Studies, Flinders University, Working Paper No. 163. 
Messinis, G. (2008). “Overeducation and overskilling in Australia: Second generation Greek-

Australians and Italian-Australians”, Centre for Strategic Economic Studies, Victoria University, Working Paper No. 37.

Messinis, G., and Olekalns, N. (2006). “Training and returns to undereducation and overeducation:

New Australian evidence”, refereed paper presented at the 35th Conference of Economists Australia, Perth, 25-27 September.

Mundlak, Y. (1978). “On the pooling of time series and cross section data”, Econometrica, 46(1), 6985.

Piracha, M., Tani, M., and Vadean, F. (2010). “Immigrant over- and under-education: The role of home country labour market experience”, IZA, Discussion Paper No. 5302.

Rumberger, R.W. (1987). “The impact of surplus schooling on productivity and earnings”, Journal of Human Resources, 22(1), 24-50.

Sicherman, N. (1991). “'Overeducation’ in the labour market”, Journal of Labour Economics, 9(2), $101-122$

Sloane, P.J., Battu, H., and Seaman, P.T. (1996). “Overeducation and the formal education/experience and training trade-off”, Applied Economics Letters, 3(8), 511-515.

Sloane, P.J., Battu, H., and Seaman, P.T. (1999). “Overeducation, undereducation and the British labour market”, Applied Economics, 31(11), 1437-1453.

Spence, M. (1973). “Job market signalling”, Quarterly Journal of Economics, 87(3), 355-374.

Thurow, L.C. (1975). Generating Inequality. New York: Basic Books.

Verdugo, R.R., and Verdugo, N.T. (1989). “The impact of surplus schooling on earnings: Some additional findings”, Journal of Human Resources, 24(4), 629-643. 


\section{Appendix A: Definition of variables}

The variables included in the wage equations are defined as follows. All dummy variables have been coded such that $1=$ yes and $0=$ no. Sample descriptives are presented in Table 1.

Inhwage: Natural logarithm of hourly wage.

under: Dummy variable to indicate under-utilisation. Under-utilisation interaction terms denoted with $a$ if under equals 1 and majori equals $1, b$ if under equals 1 and majorj equals $1, c$ if under equals 1 and majork equals $1, d$ if under equals 1 and levele equals 1.

ageyrs: Age in years at the time of the survey.

ageyrs2: Quadratic term for ageyrs.

major: Dummy variables to indicate major field of study; denoted with $a$ if sciences, $b$ if information technology, $c$ if engineering and related, $d$ if health, $e$ if education, $f$ if society and culture, $g$ if creative arts, $i$ if combined technical majors, $j$ if combined health/education, $k$ if combined society and culture/arts, base case being management and commerce.

level: Dummy variables to indicate degree level; denoted with $a$ if bachelor degree (honours), $b$ if postgraduate certificate/diploma, $c$ if masters by coursework, $d$ if postgraduate research (masters or doctoral), $e$ if postbaccalaureate, base case being bachelor degree (pass).

workstud: Dummy variable to indicate that a graduate was in paid employment during his or her final year of study.

selfemp: Dummy variable to indicate that a graduate was self employed.

ptime: Dummy variable to indicate that a graduate was employed on a part-time or casual basis. 
tenure: Number of months spent in current job at the time of the survey.

tenure2: Quadratic term for tenure.

emploc: Dummy variables to indicate employment location; denoted with $a$ if New South Wales, $b$ if Queensland, $c$ if South Australia, $d$ if Western Australia, $e$ if Tasmania, $f$ if Northern Territory, $g$ if Australian Capital Territory, base case being Victoria.

sector: Dummy variables to indicate employment sector; denoted with $a$ if mining, $b$ if manufacturing, $c$ if utilities, $d$ if construction, $e$ if wholesale and retail trade, $f$ if accommodation and food services, $g$ if transport and warehousing, $h$ if information media and telecommunications, $i$ if professional services, $j$ if administration services, $k$ if public administration, $l$ if education and training, $m$ if health care and social assistance, $n$ if arts and recreation services, $o$ if other services, base case being financial and insurance services.

lambda: Selection bias control factor (see Heckman, 1979). 
Table 1. Sample descriptives

\begin{tabular}{|c|c|c|c|c|c|}
\hline \multirow[b]{2}{*}{ Variable } & \multirow[b]{2}{*}{ Name } & \multicolumn{2}{|c|}{2007 job } & \multicolumn{2}{|c|}{2010 job } \\
\hline & & Mean & Std Dev. & Mean & Std Dev. \\
\hline Log hourly wage & lnhwage & 3.222 & 0.34 & 3.519 & 0.33 \\
\hline Under-utilised & under & 0.257 & 0.44 & 0.150 & 0.36 \\
\hline Under-utilised*technical majors & undera & 0.054 & 0.23 & 0.026 & 0.16 \\
\hline Under-utilised*health/education & underb & 0.026 & 0.16 & 0.024 & 0.15 \\
\hline Under-utilised*society and culture/arts & underc & 0.108 & 0.31 & 0.052 & 0.22 \\
\hline Under-utilised*postbaccalaureate & underd & 0.081 & 0.27 & 0.058 & 0.23 \\
\hline Female & female & 0.636 & 0.48 & 0.629 & 0.48 \\
\hline Age (years) & ageyrs & 30.658 & 10.09 & 33.811 & 10.12 \\
\hline Age (years) squared & ageyrs2 & $1,041.573$ & 733.34 & $1,245.660$ & 795.03 \\
\hline Sciences & majora & 0.083 & 0.28 & 0.075 & 0.26 \\
\hline Information technology & majorb & 0.042 & 0.20 & 0.042 & 0.20 \\
\hline Engineering and related & majorc & 0.077 & 0.27 & 0.077 & 0.27 \\
\hline Health & majord & 0.158 & 0.36 & 0.163 & 0.37 \\
\hline Education & majore & 0.123 & 0.33 & 0.123 & 0.33 \\
\hline Society and culture & majorf & 0.208 & 0.41 & 0.204 & 0.40 \\
\hline Creative arts & majorg & 0.048 & 0.21 & 0.045 & 0.21 \\
\hline Technical majors & majori & 0.202 & 0.40 & 0.195 & 0.40 \\
\hline Health/education & majorj & 0.280 & 0.45 & 0.287 & 0.45 \\
\hline Society and culture/arts & majork & 0.256 & 0.44 & 0.249 & 0.43 \\
\hline Bachelor degree (honours) & levela & 0.081 & 0.27 & 0.072 & 0.26 \\
\hline Postgraduate cert./dip. & levelb & 0.147 & 0.35 & 0.151 & 0.36 \\
\hline Masters by coursework & levelc & 0.165 & 0.37 & 0.168 & 0.37 \\
\hline Postgraduate research & leveld & 0.048 & 0.21 & 0.049 & 0.22 \\
\hline Postbaccalaureate & levele & 0.441 & 0.50 & 0.439 & 0.50 \\
\hline Paid work in final year of study & workstud & 0.911 & 0.29 & 0.915 & 0.28 \\
\hline Self employed & selfemp & 0.028 & 0.17 & 0.033 & 0.18 \\
\hline Working part time or casual & ptime & 0.184 & 0.39 & 0.136 & 0.34 \\
\hline Job tenure (months) & tenure & 26.747 & 50.47 & 42.204 & 51.16 \\
\hline Job tenure (months) squared & tenure2 & $3,261.420$ & $13,961.20$ & $4,397.562$ & $16,216.96$ \\
\hline Employed in NSW & emploca & 0.220 & 0.41 & 0.218 & 0.41 \\
\hline Employed in Qld & emplocb & 0.188 & 0.39 & 0.194 & 0.40 \\
\hline Employed in SA & emplocc & 0.127 & 0.33 & 0.124 & 0.33 \\
\hline Employed in WA & emplocd & 0.131 & 0.34 & 0.125 & 0.33 \\
\hline Employed in Tas & emploce & 0.021 & 0.14 & 0.017 & 0.13 \\
\hline Employed in NT & emplocf & 0.011 & 0.10 & 0.012 & 0.11 \\
\hline Employed in ACT & emplocg & 0.028 & 0.16 & 0.031 & 0.17 \\
\hline Mining sector & sectora & 0.016 & 0.13 & 0.019 & 0.14 \\
\hline Manufacturing sector & sectorb & 0.039 & 0.19 & 0.037 & 0.19 \\
\hline Utilities sector & sectorc & 0.016 & 0.12 & 0.017 & 0.13 \\
\hline Construction sector & sectord & 0.010 & 0.10 & 0.012 & 0.11 \\
\hline Wholesale and retail trade sector & sectore & 0.064 & 0.24 & 0.043 & 0.20 \\
\hline Accom. and food services sector & sectorf & 0.018 & 0.13 & 0.013 & 0.11 \\
\hline Transport and warehousing sector & sectorg & 0.013 & 0.11 & 0.014 & 0.12 \\
\hline Info. Media and communications sector & sectorh & 0.035 & 0.18 & 0.035 & 0.18 \\
\hline Professional services sector & sectori & 0.160 & 0.37 & 0.165 & 0.37 \\
\hline Administration services sector & sectorj & 0.014 & 0.12 & 0.015 & 0.12 \\
\hline Public administration sector & sectork & 0.122 & 0.33 & 0.138 & 0.34 \\
\hline Education and training sector & sectorl & 0.206 & 0.40 & 0.215 & 0.41 \\
\hline Health care and social assistance sector & sectorm & 0.196 & 0.40 & 0.191 & 0.39 \\
\hline
\end{tabular}


Table 1. Continued

\begin{tabular}{lccccc} 
& & \multicolumn{2}{c}{2007 job } & \multicolumn{2}{c}{2010 job } \\
\cline { 3 - 6 } \multicolumn{1}{c}{ Variable } & Name & Mean & Std Dev. & Mean & Std Dev. \\
\hline Arts and recreation services sector & sectorn & 0.016 & 0.13 & 0.014 & 0.12 \\
Other sectors & sectoro & 0.026 & 0.16 & 0.025 & 0.16 \\
\hline Observations & & \multicolumn{2}{c}{3,586} & & 3,319 \\
\hline
\end{tabular}

Notes. Authors' computations based on data from the 2010 BGS. 
Table 2. Incidence of under-utilisation amongst selected graduate cohorts in 2007 and 2010

\begin{tabular}{|c|c|c|}
\hline Graduate cohort & 2007 job (\%) & 2010 job (\%) \\
\hline \multicolumn{3}{|l|}{ Gender and age } \\
\hline Males aged 25 years and under & 30 & 12 \\
\hline Females aged 25 years and under & 34 & 18 \\
\hline Males aged over 25 years & 20 & 16 \\
\hline Females aged over 25 years & 20 & 13 \\
\hline \multicolumn{3}{|l|}{ Major field of study } \\
\hline Sciences & 38 & 18 \\
\hline Information technology & 25 & 9 \\
\hline Engineering and related & 15 & 11 \\
\hline Health & 11 & 10 \\
\hline Education & 8 & 6 \\
\hline Management and commerce & 27 & 18 \\
\hline Society and culture & 42 & 21 \\
\hline Creative arts & 41 & 21 \\
\hline \multicolumn{3}{|l|}{ Degree level } \\
\hline Bachelor degree (pass) & 32 & 16 \\
\hline Bachelor degree (honours) & 29 & 16 \\
\hline Postgraduate cert./dip. & 18 & 17 \\
\hline Masters by coursework & 16 & 11 \\
\hline Postgraduate research & 8 & 4 \\
\hline \multicolumn{3}{|l|}{ Employment characteristics } \\
\hline Paid work in final year of study & 26 & 15 \\
\hline No paid work in final year of study & 20 & 10 \\
\hline Not self employed & 26 & 15 \\
\hline Self employed & 17 & 5 \\
\hline Working full time & 21 & 14 \\
\hline Working part time or casual & 45 & 21 \\
\hline Mining sector & 8 & 9 \\
\hline Manufacturing sector & 26 & 14 \\
\hline Utilities sector & 23 & 20 \\
\hline Construction sector & 35 & 18 \\
\hline Wholesale and retail trade sector & 73 & 32 \\
\hline Accommodation and food services sector & 75 & 48 \\
\hline Transport and warehousing sector & 44 & 41 \\
\hline Information media and communications sector & 25 & 13 \\
\hline Financial and insurance services sector & 32 & 21 \\
\hline Professional services sector & 17 & 7 \\
\hline Administration services sector & 49 & 25 \\
\hline Public administration sector & 32 & 22 \\
\hline Education and training sector & 12 & 8 \\
\hline Health care and social assistance sector & 16 & 11 \\
\hline Arts and recreation services sector & 57 & 44 \\
\hline Other sectors & 45 & 31 \\
\hline Total under-utilised (\%) & 26 & 15 \\
\hline Total (n) & 3,586 & 3,319 \\
\hline
\end{tabular}

Notes. Authors' computations based on data from the 2010 BGS. 
Table 3. Transition to and from under-utilisation in 2007 and 2010

\begin{tabular}{lrrrr}
\hline & \multicolumn{3}{c}{ 2010 job } \\
\cline { 2 - 5 } \multicolumn{1}{c}{ 2007 job } & Under-utilised (\%) & Not Under-utilised (\%) & Total (\%) & Total (n) \\
\hline Under-utilised (\%) & 35 & 65 & 100 & 831 \\
Not Under-utilised (\%) & 8 & 92 & 100 & 2,488 \\
Total (\%) & 15 & 85 & 100 & - \\
Total (n) & 497 & 2,822 & - & 3,319 \\
\hline
\end{tabular}

Notes. Authors' computations based on data from the 2010 BGS. Figures are based on the subset of graduates who were employed in both survey years. 
Table 4. Wage effects of under-utilisation: main effects

\begin{tabular}{|c|c|c|c|}
\hline \multirow[b]{2}{*}{ Variable } & \multicolumn{2}{|c|}{ OLS } & \multirow[b]{2}{*}{ Fixed Effects } \\
\hline & 2007 & 2010 (Heckman) & \\
\hline \multicolumn{4}{|l|}{ Males aged 25 years and under } \\
\hline \multirow[t]{2}{*}{ Under-utilised } & -0.0163 & $-0.0835^{* *}$ & -0.0295 \\
\hline & $(0.028)$ & $(0.039)$ & $(0.021)$ \\
\hline Observations & 540 & 497 & 994 \\
\hline Prob $>$ F & 0.0000 & 0.0000 & 0.0000 \\
\hline R-squared & 0.24 & - & 0.60 \\
\hline \multirow[t]{2}{*}{ Lambda } & - & 0.1061 & - \\
\hline & & $(0.078)$ & \\
\hline \multicolumn{4}{|c|}{ Females aged 25 years and under } \\
\hline \multirow[t]{2}{*}{ Under-utilised } & $-0.0677 * * *$ & $-0.0947 * * *$ & -0.0152 \\
\hline & $(0.018)$ & $(0.022)$ & $(0.044)$ \\
\hline Observations & 1,119 & 1,014 & 2,028 \\
\hline Prob $>$ F & 0.0000 & 0.0000 & 0.0000 \\
\hline R-squared & 0.17 & - & 0.59 \\
\hline \multirow[t]{2}{*}{ Lambda } & - & $-0.1243^{* *}$ & - \\
\hline & & $(0.060)$ & \\
\hline \multicolumn{4}{|l|}{ Males aged over 25 years } \\
\hline \multirow[t]{2}{*}{ Under-utilised } & $-0.1119 * * *$ & $-0.1089 * * *$ & $-0.0508 * *$ \\
\hline & $(0.033)$ & $(0.033)$ & $(0.025)$ \\
\hline Observations & 767 & 735 & 1,470 \\
\hline Prob $>$ F & 0.0000 & 0.0000 & 0.0000 \\
\hline R-squared & 0.32 & - & 0.45 \\
\hline \multirow[t]{2}{*}{ Lambda } & - & $-0.1825^{*}$ & - \\
\hline & & $(0.098)$ & \\
\hline \multicolumn{4}{|l|}{ Females aged over 25 years } \\
\hline \multirow[t]{2}{*}{ Under-utilised } & $-0.0626 * * *$ & $-0.0751 * * *$ & $-0.0474 * *$ \\
\hline & $(0.023)$ & $(0.026)$ & $(0.022)$ \\
\hline Observations & 1,160 & 1,073 & 2,146 \\
\hline Prob $>$ F & 0.0000 & 0.0000 & 0.0000 \\
\hline R-squared & 0.24 & - & 0.44 \\
\hline \multirow[t]{2}{*}{ Lambda } & - & $-0.2414 * * *$ & - \\
\hline & & $(0.059)$ & \\
\hline \multicolumn{4}{|l|}{ Controls } \\
\hline Age & Yes & Yes & No \\
\hline Age squared & Yes & Yes & No \\
\hline Major field of study & Yes & Yes & No \\
\hline Degree level & Yes & Yes & No \\
\hline Employment characteristics & Yes & Yes & Yes \\
\hline
\end{tabular}

Notes. Authors' computations based on data from the 2010 BGS. Standard errors in parentheses. The dependent variable is log hourly wage.

* significant at $10 \%$; ** significant at $5 \%$; *** significant at $1 \%$ 
Table 5. Wage effects of under-utilisation: field of study interactions

\begin{tabular}{|c|c|c|c|}
\hline \multirow[b]{2}{*}{ Variable } & \multicolumn{2}{|c|}{ OLS } & \multirow[b]{2}{*}{ Fixed Effects } \\
\hline & 2007 & 2010 (Heckman) & \\
\hline \multicolumn{4}{|l|}{ Males aged 25 years and under } \\
\hline \multirow[t]{2}{*}{ Under-utilised } & 0.0342 & 0.0092 & -0.0112 \\
\hline & $(0.046)$ & $(0.073)$ & $(0.052)$ \\
\hline \multirow[t]{2}{*}{ Under-utilised*technical majors } & 0.0342 & -0.1326 & 0.0218 \\
\hline & $(0.059)$ & $(0.099)$ & $(0.065)$ \\
\hline \multirow[t]{2}{*}{ Under-utilised*health/education } & 0.0239 & -0.0588 & 0.1915 \\
\hline & $(0.105)$ & $(0.131)$ & $(0.126)$ \\
\hline \multirow[t]{2}{*}{ Under-utilised*society and culture/arts } & -0.1298 & -0.1511 & 0.0908 \\
\hline & $(0.065)$ & $(0.103)$ & $(0.074)$ \\
\hline Observations & 540 & 497 & 994 \\
\hline Prob $>$ F & 0.0000 & 0.0000 & 0.0000 \\
\hline R-squared & 0.23 & - & 0.60 \\
\hline \multirow[t]{2}{*}{ Lambda } & - & $0.1547 * *$ & - \\
\hline & & $(0.077)$ & \\
\hline \multicolumn{4}{|l|}{ Females aged 25 years and under } \\
\hline \multirow[t]{2}{*}{ Under-utilised } & $-0.1063 * * *$ & $-0.1508 * * *$ & -0.0580 \\
\hline & $(0.032)$ & $(0.043)$ & $(0.040)$ \\
\hline \multirow[t]{2}{*}{ Under-utilised*technical majors } & 0.0143 & -0.0471 & 0.0024 \\
\hline & $(0.047)$ & $(0.065)$ & $(0.061)$ \\
\hline \multirow[t]{2}{*}{ Under-utilised*health/education } & 0.0804 & 0.0756 & 0.0673 \\
\hline & $(0.054)$ & $(0.066)$ & $(0.070)$ \\
\hline \multirow[t]{2}{*}{ Under-utilised*society and culture/arts } & $0.0702 *$ & $0.1257 * *$ & 0.0720 \\
\hline & $(0.039)$ & $(0.054)$ & $(0.047)$ \\
\hline Observations & 1,119 & 1,014 & 2,028 \\
\hline Prob $>$ F & 0.0000 & 0.0000 & 0.0000 \\
\hline R-squared & 0.16 & - & 0.59 \\
\hline \multirow[t]{2}{*}{ Lambda } & - & $-0.1260 * *$ & - \\
\hline & & $(0.060)$ & \\
\hline \multicolumn{4}{|l|}{ Males aged over 25 years } \\
\hline \multirow[t]{2}{*}{ Under-utilised } & $-0.1520 * * *$ & $-0.1127 * * *$ & -0.0329 \\
\hline & $(0.052)$ & $(0.048)$ & $(0.037)$ \\
\hline \multirow[t]{2}{*}{ Under-utilised*technical majors } & -0.0572 & 0.1050 & -0.0436 \\
\hline & $(0.078)$ & $(0.086)$ & $(0.060)$ \\
\hline \multirow[t]{2}{*}{ Under-utilised*health/education } & $0.2688 * * *$ & -0.0199 & -0.0842 \\
\hline & $(0.104)$ & $(0.097)$ & $(0.084)$ \\
\hline \multirow[t]{2}{*}{ Under-utilised*society and culture/arts } & 0.0847 & -0.0826 & 0.0248 \\
\hline & $(0.081)$ & $(0.082)$ & $(0.072)$ \\
\hline Observations & 767 & 735 & 1,470 \\
\hline Prob $>$ F & 0.0000 & 0.0000 & 0.0000 \\
\hline R-squared & 0.32 & - & 0.45 \\
\hline \multirow[t]{2}{*}{ Lambda } & - & $-0.1745^{*}$ & - \\
\hline & & $(0.094)$ & \\
\hline \multicolumn{4}{|l|}{ Females aged over 25 years } \\
\hline Under-utilised & $-0.0954 * *$ & -0.0362 & -0.0501 \\
\hline & $(0.042)$ & $(0.049)$ & $(0.039)$ \\
\hline Under-utilised*technical majors & 0.0501 & -0.0218 & 0.0499 \\
\hline & $(0.076)$ & $(0.088)$ & $(0.072)$ \\
\hline Under-utilised*health/education & -0.0191 & -0.0589 & -0.0500 \\
\hline & $(0.067)$ & $(0.072)$ & $(0.061)$ \\
\hline
\end{tabular}


Table 5. Continued

\begin{tabular}{lrrr}
\hline & \multicolumn{2}{c}{ OLS } & \\
\cline { 2 - 3 } \multicolumn{1}{c}{ Variable } & 2007 & 2010 (Heckman) & Fixed Effects \\
\hline Under-utilised*society and culture/arts & 0.0831 & -0.0590 & 0.0236 \\
Observations & $(0.056)$ & $(0.065)$ & $(0.056)$ \\
Prob > F & 1,160 & 1,073 & 2,146 \\
R-squared & 0.0000 & 0.0000 & 0.0000 \\
Lambda & 0.23 & - & 0.44 \\
& - & $(0.059)$ & - \\
\hline Controls & & & No \\
Age & & Yes & No \\
Age squared & Yes & Yes & No \\
Major field of study & Yes & Yes & No \\
Degree level & Yes & Yes & Yes \\
Employment & Yes & Yes & Yes \\
\hline
\end{tabular}

Notes. Authors' computations based on data from the 2010 BGS. Standard errors in parentheses. The omitted base case is Management and commerce. The dependent variable is log hourly wage.

* significant at $10 \%$; ** significant at $5 \%$; *** significant at $1 \%$ 
Table 6. Wage effects of under-utilisation: degree level interactions

\begin{tabular}{|c|c|c|c|}
\hline \multirow[b]{2}{*}{ Variable } & \multicolumn{2}{|c|}{ OLS } & \multirow[b]{2}{*}{ Fixed Effects } \\
\hline & 2007 & 2010 (Heckman) & \\
\hline \multicolumn{4}{|l|}{ Males aged 25 years and under } \\
\hline \multirow[t]{2}{*}{ Under-utilised } & -0.0171 & $-0.0976 * *$ & 0.0341 \\
\hline & $(0.031)$ & $(0.042)$ & $(0.031)$ \\
\hline \multirow[t]{2}{*}{ Under-utilised*postbaccalaureate } & -0.0269 & 0.0961 & -0.0351 \\
\hline & $(0.065)$ & $(0.114)$ & $(0.081)$ \\
\hline Observations & 540 & 497 & 994 \\
\hline Prob $>$ F & 0.0000 & 0.0000 & 0.0000 \\
\hline R-squared & 0.22 & - & 0.60 \\
\hline \multirow[t]{2}{*}{ Lambda } & - & 0.1003 & - \\
\hline & & $(0.079)$ & \\
\hline \multicolumn{4}{|l|}{ Females aged 25 years and under } \\
\hline \multirow[t]{2}{*}{ Under-utilised } & $-0.0575 * * *$ & $-0.1023 * * *$ & -0.0107 \\
\hline & $(0.019)$ & $(0.025)$ & $(0.023)$ \\
\hline \multirow[t]{2}{*}{ Under-utilised*postbaccalaureate } & -0.0487 & 0.0248 & -0.0190 \\
\hline & $(0.036)$ & $(0.049)$ & $(0.046)$ \\
\hline Observations & 1,119 & 1,014 & 2,028 \\
\hline Prob $>$ F & 0.0000 & 0.0000 & 0.0000 \\
\hline R-squared & 0.17 & - & 0.59 \\
\hline \multirow[t]{2}{*}{ Lambda } & - & $-0.1258 * *$ & - \\
\hline & & $(0.059)$ & \\
\hline \multicolumn{4}{|l|}{ Males aged over 25 years } \\
\hline \multirow[t]{2}{*}{ Under-utilised } & -0.0734 & $-0.1235 * * *$ & $-0.0974 * *$ \\
\hline & $(0.049)$ & $(0.052)$ & $(0.042)$ \\
\hline \multirow[t]{2}{*}{ Under-utilised*postbaccalaureate } & -0.0731 & 0.0133 & 0.0716 \\
\hline & $(0.063)$ & $(0.064)$ & $(0.052)$ \\
\hline Observations & 767 & 735 & 1,470 \\
\hline Prob $>$ F & 0.0000 & 0.0000 & 0.0000 \\
\hline R-squared & 0.31 & - & 0.45 \\
\hline \multirow[t]{2}{*}{ Lambda } & - & $-0.1942 * *$ & - \\
\hline & & $(0.099)$ & \\
\hline \multicolumn{4}{|l|}{ Females aged over 25 years } \\
\hline \multirow[t]{2}{*}{ Under-utilised } & -0.0273 & $-0.0962 * *$ & $-0.1163^{* * *}$ \\
\hline & $(0.034)$ & $(0.039)$ & $(0.033)$ \\
\hline \multirow[t]{2}{*}{ Under-utilised*postbaccalaureate } & $-0.0809 *$ & 0.0220 & $0.1299 * * *$ \\
\hline & $(0.045)$ & $(0.052)$ & $(0.045)$ \\
\hline Observations & 1,160 & 1,073 & 2,146 \\
\hline Prob $>$ F & 0.0000 & 0.0000 & 0.0000 \\
\hline R-squared & 0.21 & - & 0.44 \\
\hline \multirow[t]{2}{*}{ Lambda } & - & $-0.2323 * * *$ & - \\
\hline & & $(0.060)$ & \\
\hline \multicolumn{4}{|l|}{ Controls } \\
\hline Age & Yes & Yes & No \\
\hline Age squared & Yes & Yes & No \\
\hline Major field of study & Yes & Yes & No \\
\hline Degree level & Yes & Yes & No \\
\hline Employment & Yes & Yes & Yes \\
\hline
\end{tabular}

Notes. Authors' computations based on data from the 2010 BGS. Standard errors in parentheses. The omitted base case is pass bachelor degree. The dependent variable is log hourly wage.

* significant at $10 \%$; ** significant at $5 \%$; *** significant at $1 \%$ 